\title{
QUALITATIVE PSYCHOLOGICAL EFFECTS OF POLITICAL INFORMATION TO HIGH SCHOOL STUDENTS ${ }^{1}$
}

\author{
Irina Samuylova \\ Department of Political Psychology, Faculty of Psychology, Saint-Petersburg State University
}

(Russian Federation)

\begin{abstract}
The paper presents the results of an empirical study of high school students' assessment of the qualitative characteristics of political information and its relationship with the emergence of emotional (affective) and cognitive-behavioral reactions. Teenagers and young people are especially sensitive to media influence. Having a clear understanding of the nature of politics, its goals, objectives, means and other subtleties at this age is rare. This makes young people vulnerable to suggestion and manipulation. Violation of the principles of information and psychological security can lead to General neurotization, the formation of depressive States, increased anxiety, distortion of the picture of the world, the manifestation of other negative effects in the younger generation.

In 2016-2018, an empirical study was conducted, which tested hypotheses about the relationship between the assessment of high school students (senior pupils) of the qualitative characteristics of political information, the level of their media competence and self-assessment of their own mental states of recipients caused by the impact of political information.

As the object of study were selected high school students (10-11 grade) from St. Petersburg and Mirny, Republic Sakha, Yakutia, a total of 115 people ( 75 girls and 40 boys), aged 15 to 18 years (average age 16). Data was collected using questionnaires.

Analysis of the results of the study showed that the most important sources of political information for high school students are the Internet, the mass media and the family, the least important sources are religious associations. Assessing the political information, high school students especially noted such qualities as clarity, discrediting and disintegrating character, low level of disorganization.

In the process of interaction with political information, high school students actualized concealment as a mechanism of psychological protection (delay or rejection of reactions, concealment of information about yourself).

In general, the study identified and described the main mental areas of potential psychological and political effects in the interaction with political information. Specific psychological characteristics that can be subject to potential transformations, as well as factors of "motivation for political participation" and political "conformism-nonconformism" are highlighted. The quality of political information contributes to the emergence of conditionally "positive" psychological effects (in terms of the stability of the political system), like "the effect of involvement" and the development of political conformism. The qualities of falsifying, misinforming and disorienting political information contribute to the emergence of "negative" affective (hatred, antipathy, criticality) and cognitive-behavioral effects (rivalry, radicalism).
\end{abstract}

Keywords: Political information, psychological effects, information psychological safety, high school students.

\section{Introduction}

Despite the development of the topic of media influence in psychological science, the specificity of the impact of political information is not enough studied today. As a rule, researchers focus on the study of negative aspects in a specific area of information (advertising, propaganda, transfer of political experience and political culture), without taking into account the effects associated with the generalized perception of political information.

${ }^{1}$ With the financial support of RFFI: project «Media image of Russia in context of national security», № 19-013-00725 
Minors are particularly sensitive to the effects of the media, namely adolescents and young men who are on the verge of adulthood and the acquisition of new civil rights. The transition to the stage of active political participation is accompanied by the formation of a system of beliefs and personal values, as well as the life and political position of the young personality. National policy and social conditions of life, as well as political information, assimilated by a senior high school student, are of tremendous importance. The manifestation of various psychological effects can be expressed most vividly in this age group.

Studying the designated problem will help establish whether there is a relationship between how senior high school students assess political information and what ideas about politics they have? Of particular interest is the definition of the relationship between the qualities of political information and the willingness to assimilate and relay political attitudes and values, as well as mental states of young people that are caused by political messages.

\section{Design}

The organization of the study included three stages. At the first, preparatory, stage, in order to identify and systematize the various psychological effects resulting from interaction with political information, a preliminary analytical review of the literature on the features of the psychological impact of mass and political information was conducted. The specific signs of political information and psychological characteristics of a person, which may be affected by media impact, were analyzed.

At the main stage, an empirical study was conducted aimed at studying the psychological characteristics that are actualized during the interaction of high school students with political information. Data collection was carried out using a written questionnaire (the time of filling is not more than 45 minutes). The questionnaire was formed from specially selected methods (see Methods). The study tested the hypothesis that there is a correlation between assessments of political information, the level of media competence and mental states experienced by high school students as a result of its common perception. The relationship between the qualities of political information and the parameters of social subordination / social aggressiveness of the respondents was also investigated.

For qualitative and quantitative processing of the obtained data, the following methods were used: content analysis, correlation analysis, factor analysis (method of principal components).

The obtained quantitative results were subjected to further interpretation in order to establish the specific qualitative psychological effects of the influence of political information on high school students.

\section{Objectives}

The main objective of the research is to identify qualitative psychological effects arising from the interaction of high school students with political information. The variety of existing forms of political information, types of audience, channels of communication and impact objectives prompted us not to limit ourselves to studying the effects of specific stimulus, which can be established by conducting an experiment, but to analyze the overall result of the intellectual expansion.

The subject of the research are specific psychological characteristics affecting the emotional, cognitive and behavioral spheres of the psyche: mental states, level of media competence, socio-political beliefs, parameters of social aggressiveness / social subordination.

Senior high school students (grades 10-11) from city Saint-Petersburg (Russia) and city Mirny, Republic of Sakha (Yakutia, Russia) were chosen as the object of study. A total of 115 respondents ( 75 girls and 40 boys), aged 15 to 18 years old (mean age 16.7 ).

\section{Methods}

During the research we used the method of theoretical analysis of literature, questionnaire, method of content analysis.

Questionnaire method - a method that uses a specially designed questionnaire question list as a means of collecting information from a respondent. The questionnaire procedure involves a written survey using prepared forms.

1) Questionnaire for identifying representations about the qualities of political information (A.Shlionsky, I.Samuylova, 2007). The questionnaire consists of 22 statements, 5 gradations of the degree of agreement are given (from 1 to 5 points). As a result of filling in the questionnaire, the following are revealed: psychological defense mechanisms (care, blocking, control, hiding) [Grachev, 1998], actualized in the process of interaction with information; criteria of information and psychological security (completeness, clarity, trust, relevance); qualities of adequate (sufficiency, clarity, objectivity, 
consistency, organization, concreteness, practicality and necessity) and inadequate political information (falsifying, disorienting, discrediting, destabilizing, misinforming, disorganizing, demoralizing, disintegrating) [Yuriev, 1992].

2) Questionnaire to identify the level of political media competence [Bakuleva, 2015]. It is aimed at studying the degree of emotional involvement in the perception of political messages, the propensity to analyze and interpret information of a political nature, knowledge about the features of the media, as well as the frequency of contacts with the media.

3) Methods for assessing mental states resulting from interaction with political information (to obtain subjective, deferred assessments of conditions arising from respondents during interaction with political information) [Yuryev, 1995; Bianki, 2006].

4) Method of measuring levels of social aggressiveness and social subordination [Samuylova, 2015]. Developed on the basis of the scheme of the psychological and political stability of society proposed by A.I. Yuriev [Yuriev, 1992]. It consists of 8 statements that diagnose the characteristics of the social subordination of the respondent (indifference, conservatism, adaptability, dependency) and social aggressiveness (initiative, radicalism, rivalry, creativity). The respondent expressed the degree of his agreement with each of the proposed statements (a scale from 1 to 5 points).

5) The method of measuring the system of political beliefs (operational code). Developed on the basis of A. George's operational coding theory [George, 1969]. It consists of 10 statements that diagnose a person's ideas about politics: philosophical (about the nature of politics, predictability of the future, the role of chance, etc.) and instrumental (about means of achieving goals, their realism, risk, level of motivation, etc.) issues. The respondent expressed the degree of his agreement with each of the proposed statements (a scale from 1 to 5 points).

For high-quality processing of the obtained data, the method of content analysis was used. The methods of mathematical statistics were used for quantitative data analysis: 1) descriptive statistics methods (means, standard deviation, etc.); 2) the correlation analysis (Pearson), for detecting the presence of connections between the metric variables under study; 3 ) factor analysis (reduction of dimension). The processing of initial data, calculation of results and statistical analysis were performed using the methods of mathematical statistics included in Microsoft Excel software and IBM SPSS Statistics 23.0.0.

\section{Discussion}

The theoretical analysis showed that informational and psychological, including politico-informational, impact causes a person a number of psychological effects that affect perceptual (sensations, perception), affective (mental states, emotions, feelings), cognitive (ideas, attitudes, beliefs, knowledge) and behavioral (motives, will, activity) areas.

Perceptual sphere affects the perception of political information and subjects of communication. Depending on the nature of the message being transmitted, the transmission, the channel of transmission and the direction of influence, various psychological effects can manifest themselves. For example, the perception of a speech by an authoritative politician may occur with a distortion created by the halo effect.

The affective sphere correlates with the concept of actualization of the mental states of a person as a reaction to political incentives developed for political psychology [Yuriev, 1995].

The cognitive sphere includes mechanisms for collecting and processing information, political views and beliefs of the person. Changing and shaping ideas about the nature of politics, specific events or groups of people most often becomes the goal of political communication. Accordingly, its expected effects often affect this particular area.

The behavioral sphere includes the needs, motives and forms of political behavior. Control and inducements of the political activity of the population are one of the direct tasks of the political system. Consequently, this area is also necessarily affected in the process of political communication.

The effect of political information is positive when it contributes to political socialization, that is, human development as a member of a politicized society, a participant in the political process. In the case of inverse changes, the effect may be negative. Also differ: individual (intrapersonal) and group effects; short-term effects (changes that have arisen under the influence of information are not permanent and disappear after some time) and long-term effects (changes persist for a period much longer than the duration of the impact itself). The effect may manifest itself situational and not extend to a person's daily life, however, the opposite is also true - some effects may have a totality of manifestation (for example, a gap in thinking). According to the objectives of the impact can be distinguished: the expected or side effect. The last one can be both positive and negative. 
Empirically, is was tested that there is a relationship between assessments of political information, the level of media competence and mental states experienced by high school students as a result of its holistic perception. The relationship between the qualities of political information and the parameters of social subordination / social aggressiveness of the respondents was also under investigation.

The general level of media competence of senior high school students can be defined as medium, $57 \%$ of respondents $(\mathrm{M}=21.67, \sigma= \pm 8.991)$, low $-29 \%$, high $-21 \%$.

The content analysis of the definitions of the concept "political information" that were given by respondents (the answer to the open question "Political information is ...") allowed us to establish general tendencies of understanding of political information by senior high school students (H.Lasswell's communication model was used for the analysis).

What is said? $75.8 \%$ of answers: "information about politics", "about the sphere of politics" (27\%), "about the state of the country" (15\%), "about events, situations" (14\%), "about foreign countries" $(13 \%)$. The last of answers are not significant (no more than 5\%): about political activity, about current incidents, about politicians, military-political news, about the government, propaganda information, "false information" and "theory of politics" (1.8\%). Most of the answers affect the content side of the information, a large proportion of formal-logical answers.

What effect? $10.6 \%$ of answers: awareness, familiarization $(7.9 \%)$, agitation $(1.8 \%)$, inducement to action $(0.9 \%)$, misleading, misinformation $(0.9 \%)$.

Who is talking to? $6.2 \%$ of responses: society (3.5\%), citizens (1.8\% of people), population $(0.9 \%)$.

Who is talking? 2.6\% of answers: "parties and their members", "mass media", "top power". In most cases, the source of political information is not called.

Where (by what channel)? 1.8\% answers: books, television, radio.

Thus, high school students, making a judgment on political information in general, do not concentrate on the addressee or addressee of messages, as well as specific technical means of their transmission. Political information, to a greater extent, is perceived from the point of view of the subject and consequences of perception by the audience.

The most important sources of political information credit for senior high school students (among 12 sources) are the Internet, the mass media and the family, the least important sources religious associations.

By its qualities, political information is assessed by young people as clear $(M=3.9, \sigma=0.9)$ and not disruptive $(M=2.4, \sigma=1.2)$, but discrediting $(M=3.9, \sigma=1)$ and disintegrating $(M=3.6, \sigma=1.2)$. Thus, political information, despite its clarity, can, according to high school students, mislead people and divide society, divide it into opposing parts. The main mechanism of psychological protection of respondents is the hiding mechanism $(M=2.5, \sigma=1.2)$, which suggests that high school students tend to delay or reject reactions to incoming information, possibly concealing feelings and expressions of emotions.

Political information causes negative states: disturbance $(\mathrm{M}=2.3, \sigma=0.8)$, hostility $(\mathrm{M}=2.5$, $\sigma=0.9)$, tension $(\mathrm{M}=2.3, \sigma=0.9)$, anxiety $(\mathrm{M}=2.4, \sigma=1.1)$ and criticality $(\mathrm{M}=2.3, \sigma=1.1)$. This suggests that the existing impact of political information is perceived by them as negative, causes discontent, mistrust, doubts about its reliability and can push away high school students from the political sphere. At the same time, a state of curiosity is manifested, that is, a need for information, there is interest in it, but apparently it is not being satisfied.

Analysis of the results of measuring social aggressiveness/social subordination showed the severity of parameters of radicalism $(M=2.2, \sigma=1.2)$, competition $(M=3.6, \sigma=1.2)$, indifference $(M=2.2, \sigma=1.2)$, dependency $(M=3.5, \sigma=1.3)$ and lack of initiative $(M=2.3, \sigma=1.2)$. High school students have an interest in a political system that seems to be unsatisfactory, requiring changes, but they are not yet ready to take the initiative and take responsibility for any actions.

The policy is presented to high school students as a hostile world $(M=3.8,6=1.2)$, where it is necessary to take risks in order to achieve goals $(M=2.5, \sigma=1.3)$, the achievement of which is quite realistic $(M=2.1, \sigma=0.9)$. As a means of achievement in politics, the word $(M=3.6, \sigma=1.5)$ and teamwork $(\mathrm{M}=2, \sigma=1.3)$ prevail.

As a result of the correlation analysis, the hypothesis was confirmed that there is a relationship between the assessment of the quality of political information by high school students, their level of media competence, political beliefs, self-esteem of mental states and social subordination/social aggressiveness parameters.

The factor analysis allowed us to distinguish two main factors: the factor of incentives for political participation (factor weight=8.31) and the factor of conformism-non-conformism (factor weight=7.29). 
The variables included in the first factor cause the emergence of the "engagement effect", which can be defined as an increase in interest in politics in the process of updating the motives for political participation that occurs as a result of adequate intellectual expansion. Increasing the necessity and practicality of political information causes a mental state of curiosity (affect) in a high school student, "turning off" the mechanisms of psychological defenses, increasing the level of motivation (behavior). Thus, the "engagement effect" is caused by the necessity, practicality of political information and affects all three selected areas of psychological effects (affective, cognitive and behavioral).

The variables of the second factor are arranged in a dichotomy, each pole of which corresponds to the "contentment-dissatisfaction" of the political system, the "social subordination/social aggressiveness" of the senior pupil and cause manifestations of opposite effects. The objectivity and sufficiency of political information contributes to the emergence of positive mental states and social subordination. Conversely, falsifying, misinforming and misleading information causes negative affective (hate, antipathy, criticality) and cognitive-behavioral (radicalism, rivalry) effects.

\section{Conclusions}

The research allowed us to identify and describe the main mental areas of the potential occurrence of qualitative psychological effects as a result of interaction with political information: affective, perceptual, cognitive and behavioral.

It was confirmed that there is a relationship between the assessment of the quality of political information by senior high school students, their level of media competence, political beliefs, self-assessment of mental states and parameters of social subordination / social aggressiveness. The factors of incentives for political participation and the factor of conformism-non-conformism are highlighted. The "effect of engaging in politics" has also been identified and described.

When a nationwide system of political education is not so strong or crucial, the presence and nature of the psychological effects of the influence of political information can become the defining criteria for evaluating the effectiveness of the political socialization of young people. Thus, we have touched upon a topic that requires careful study by psychologists, which provides a great deal of scope for scientific research. As a promising direction, we see the study of the specific manifestations of the obtained psychological effects in different age and social groups of people, deepening the theoretical and methodological development of the problem, conducting experiments to study the perceptual sphere that we ignored and confirm the effects established in this study.

\section{References}

Bakuleva K.K. (2015) Psihologicheskie aspekty izuchenija politicheskoj mediakompetentnosti // Vestnik Sankt-Peterburgskogo universiteta. Serija 12: Psihologija. Sociologija. Pedagogika, 2014. - № 3. Pp. 121-127. Bakuleva K.K. (2005) Psychological aspects of the study of political media competence // Bulletin of St. Petersburg University. Series 12: Psychology. Sociology. Pedagogy, 2014. - № 3. - Pp. 121-127.

Bianki V.A. (2006) Psihologija formirovanija politicheskogo prostranstva Sankt-Peterburga: dis. na soisk. uchen. step. kand. psih. nauk (19.00.12) / Saint-Petersburg. Bianki V.A. (2006) Psychology of the formation of the political space of St. Petersburg. St. Petersburg.

George A. (1969) The "Operational Code": A Neglected Approach to the Study of Political Leaders and Decision-Making. International Studies Quarterly. Vol. 13.

Grachev G.V. (1998) Informacionno-psihologicheskaja bezopasnost' lichnosti: sostojanie i vozmozhnosti psihologicheskoj zashhity (1998). Moscow. Grachev G.V. (1998) Information and psychological security of the individual: state and possibilities of psychological protection. - M.: RGAS, 1998.

Yuriev A.I. (1992) Vvedenie v politicheskuju psihologiju. - SPb.: Izd. S.-Peterburgskogo un-ta, 1992. Yuriev A.I. (1992) Introduction to political psychology. - SPb.: Ed. St. Petersburg University, 1992. 